\title{
Radiologically Unusual Presentation of Cholesterol Granuloma in the Sphenoid Sinus
}

\author{
Da Hee Kim ${ }^{1}$, Seung-Koo Lee ${ }^{2}$, Chang-Hoon Kim ${ }^{1,3}$, and Hyung-Ju Cho ${ }^{1,3}$ \\ ${ }^{1}$ Departments of Otorhinolaryngology, ${ }^{2}$ Radiology, Yonsei University College of Medicine, Seoul; and \\ ${ }^{3}$ The Airway Mucus Institute, Yonsei University College of Medicine, Seoul, Korea
}

\author{
점액류낭종으로 오인된 접형동에 발생한 콜레스테롤 육아종 \\ 김다희 $^{1} \cdot$ 이승구 $^{2} \cdot$ 김창훈 $^{1,3} \cdot$ 조형주 ${ }^{1,3}$ \\ 연세대학교 의과대학 이비인후과학교실, ${ }^{1}$ 연세대학교 의과대학 영상의학과학교실, ${ }^{2}$ 기도점액연구소 ${ }^{3}$
}

\author{
Received December 22, 2014 \\ Revised March 3, 2015 \\ Accepted March 4, 2015 \\ Address for correspondence \\ Hyung-Ju Cho, MD, PhD \\ Department of Otorhinolaryngology, \\ Yonsei University College of Medicine, \\ 50-1 Yonsei-ro, Seodaemun-gu, \\ Seoul 03722, Korea \\ Tel +82-2-2228-3602 \\ Fax +82-2-393-0580 \\ E-mail hyungjucho@yuhs.ac
}

Cholesterol granuloma is a histopathological diagnosis with features of cholesterol clefts, foreign body giant cells, and macrophages filled with hemosiderin. It is commonly found in the mastoid or petrous apex, but the involvement of paranasal sinuses is very rare. Radiologically, cholesterol granuloma show typical findings of hyperintense signals on both T1- and T2-weighted images on magnetic resonance imaging (MRI). We report two cases of cholesterol granuloma in the sphenoid sinus, which were first misinterpreted as mucoceles due to unusual MRI images. Korean J Otorhinolaryngol-Head Neck Surg 2015;58(9):641-5

Key Words Cholesterol granuloma - Magnetic resonance imaging · Mucocele · Sphenoid sinus.

\section{Introduction}

Cholesterol granuloma is a histopathological term used to describe fibrous granulation tissue consisting of cholesterol clefts, foreign body giant cells, and macrophages filled with hemosiderin pigments. ${ }^{1)}$ It is commonly found in the middle ear cavity, mastoid bone, or petrous apex region. ${ }^{1-4)}$ The paranasal sinus (PNS) is a rare location for cholesterol granuloma development, and involvement of the sphenoid sinus is extremely rare among paranasal sinuses. ${ }^{1,2,5-7)}$

The typical radiologic feature of cholesterol granuloma on computed tomography (CT) is a well-circumscribed expansile lesion with soft tissue density. Cholesterol granuloma and mucocele show the same characteristics on $\mathrm{CT}$, making the two diagnoses difficult to differentiate. ${ }^{8)}$ Magnetic resonance imaging (MRI) is very helpful to differentiate between the two diseases. On T1-weighted images (T1WI), cholesterol granuloma classically demonstrates hyperintense signal, whereas mucocele shows hypointense signal. ${ }^{2,5,7)}$

Here, we report two rare cases of sphenoid cholesterol granuloma that were radiologically misdiagnosed as mucocele.

\section{Case}

\section{Case I}

A 67-year-old male patient had experienced lightheadedness, sometimes leading to syncope. Brain CT evaluation showed a mass lesion in the sphenoid sinus, for which he was referred to our clinic. The patient had no nasal trauma history but had undergone Caldwell-Luc operation due to chronic sinusitis during childhood. The patient had no nasal or visual symptoms. Endoscopic examination showed no mass or abnormal findings in the nasal cavity.

PNS CT revealed a $2.8-\mathrm{cm}$, non-enhancing, expansile lesion with soft tissue density in the left sphenoid sinus. The roof and floor of the sphenoid sinus were intact, but thinning 
of the bone was noted on the lateral wall (Fig. 1). On MRI, a similar sized expansile lesion showed T1 hypo-intensity and heterogeneous T2 hyper-intensity, suggesting a mucocele (Fig. 2).

Endoscopic sphenoid sinusotomy was performed via the transethmoidal approach. The anterior wall of the sphenoid sinus bulged out and was opened widely with various endoscopic instruments. The sphenoid sinus was filled with viscous yellowish-brown material. All contents were removed, and the area was irrigated with saline. Partial bony erosion of the sphenoid sinus lateral wall confirmed preoperative CT results. Fortunately, cerebrospinal fluid (CSF) leakage was
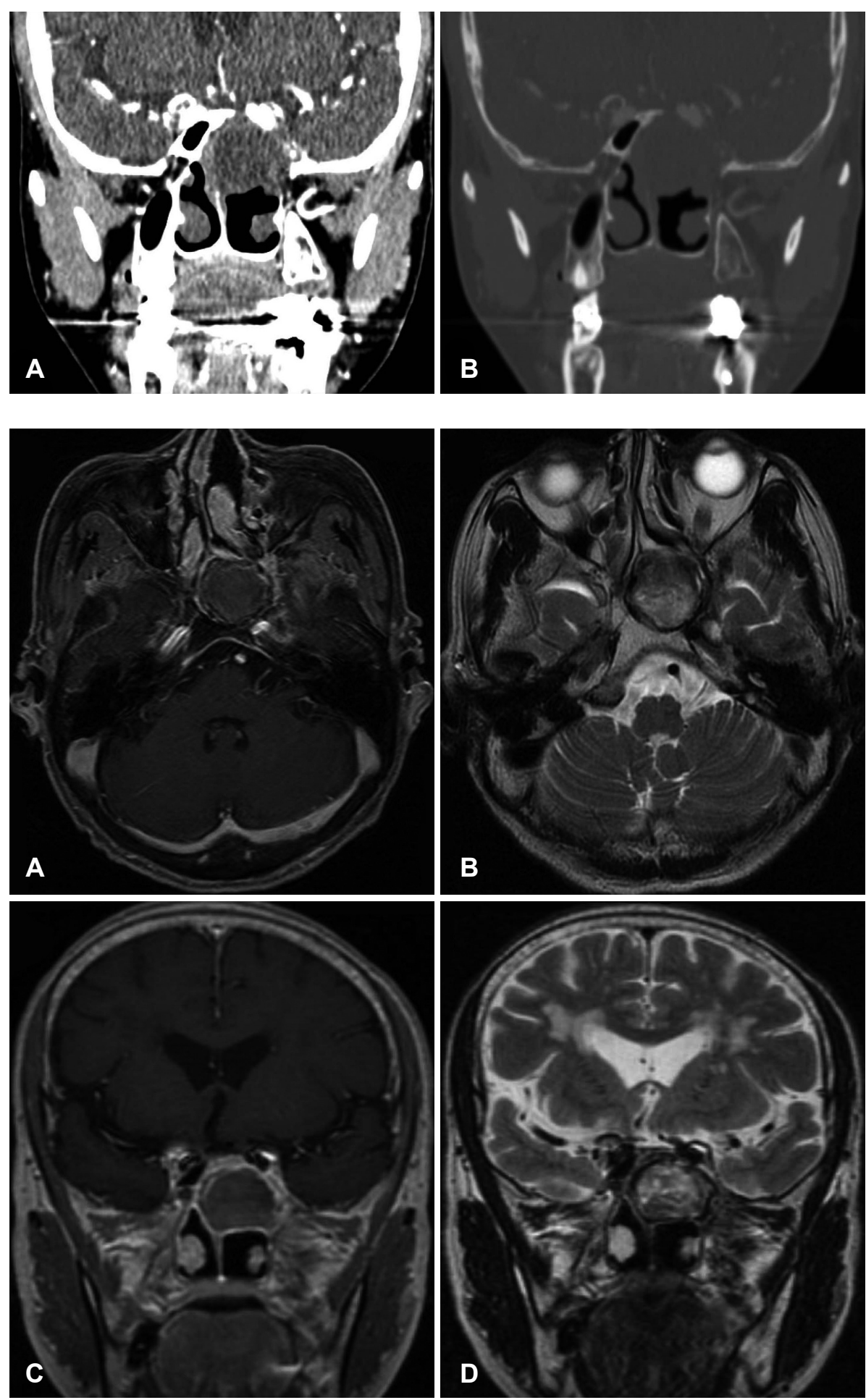

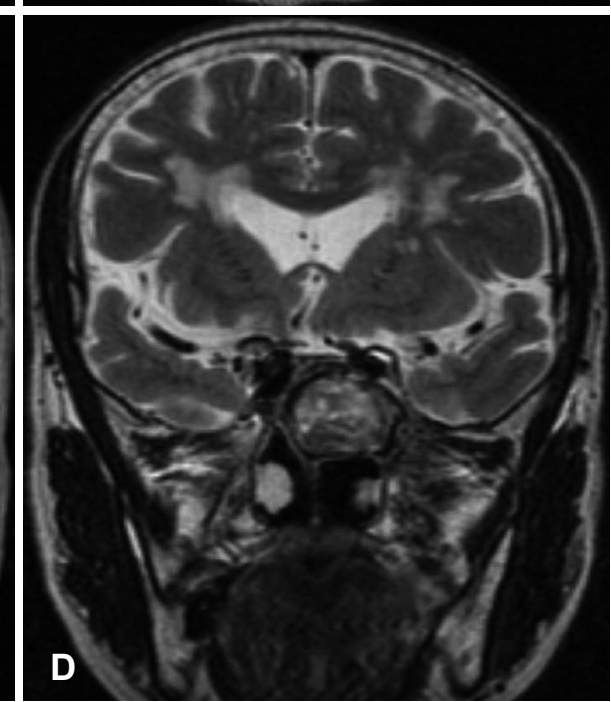

Fig. 1. Paranasal sinus CT images from patient 1. A 2.8-cm, non-enhancing, expansile lesion with soft tissue density in the left sphenoid sinus. The roof and floor of the sphenoid sinus were intact, but thinning of the bone was noted on the lateral wall. Soft tissue density window $(A)$. Bone density window $(\mathrm{B})$.
Fig. 2. PNS MRI images from patient 1. A 2.5-cm, expansile lesion in the left sphenoid sinus, with low signal intensity on $\mathrm{T} 1$-weighted images (A: axial, C: coronal) and high signal intensity on T2-weighted images (B: axial, D: coronal). PNS: paranasal sinus. 
not observed during the operation. The surgical specimen was submitted for pathologic review. Interestingly, the pathologic result revealed scattered fragments of acellular proteinaceous material, cholesterol clefts, and aggregation of histio-

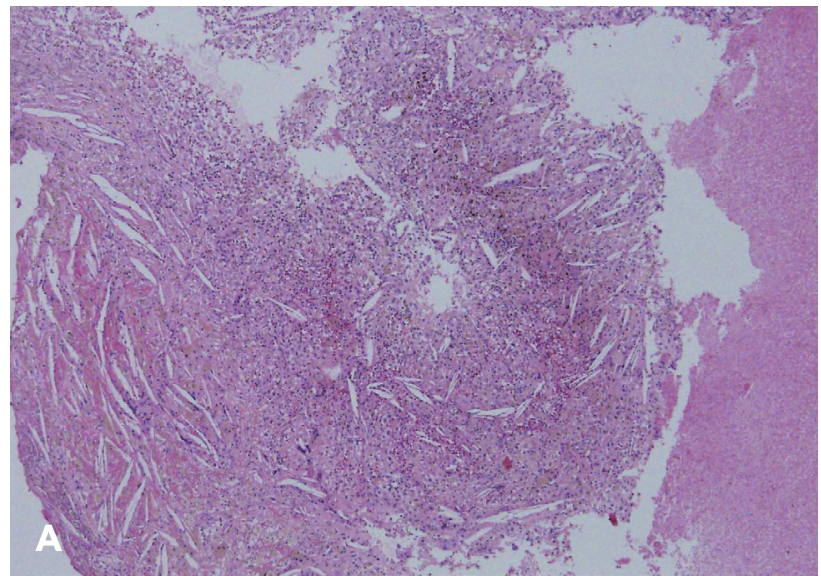

cytes, suggesting cholesterol granuloma (Fig. 3). The patient has been in follow-up for one year after surgery, and no recurrence has been noted.

Fig. 3. Pathologic review showed scattered fragments of acellular proteinaceous material, cholesterol clefts, and aggregation of histiocytes, suggesting cholesterol granuloma $(A: \times 40, B: \times 100)$.
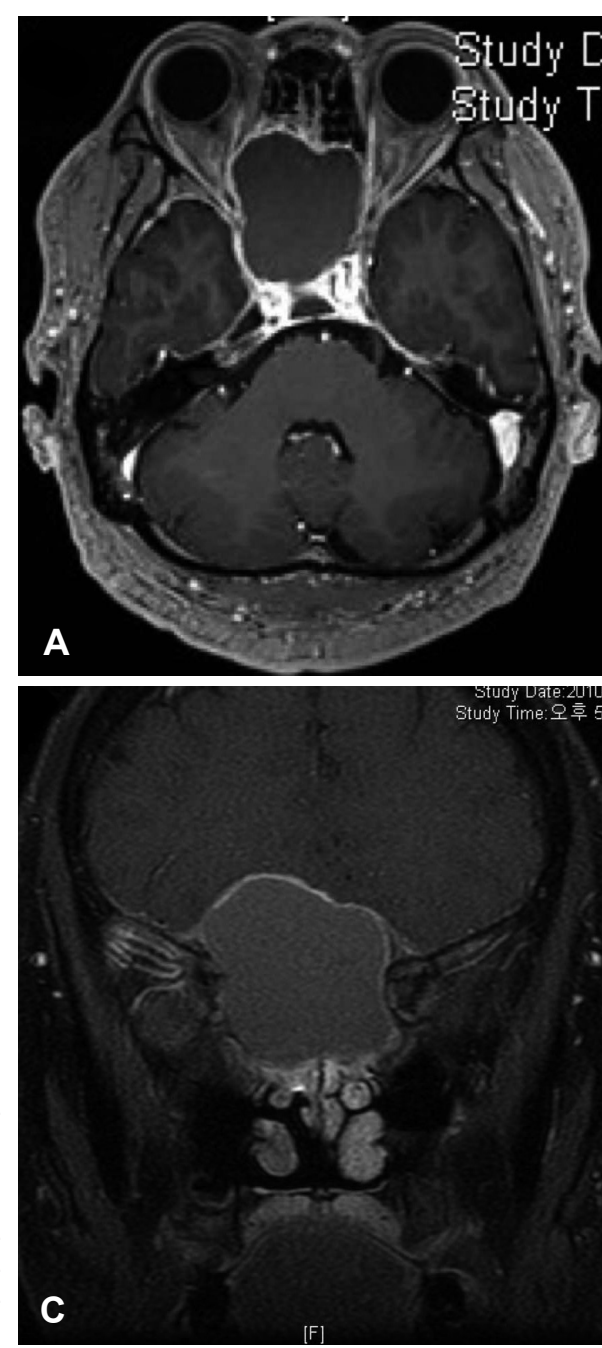
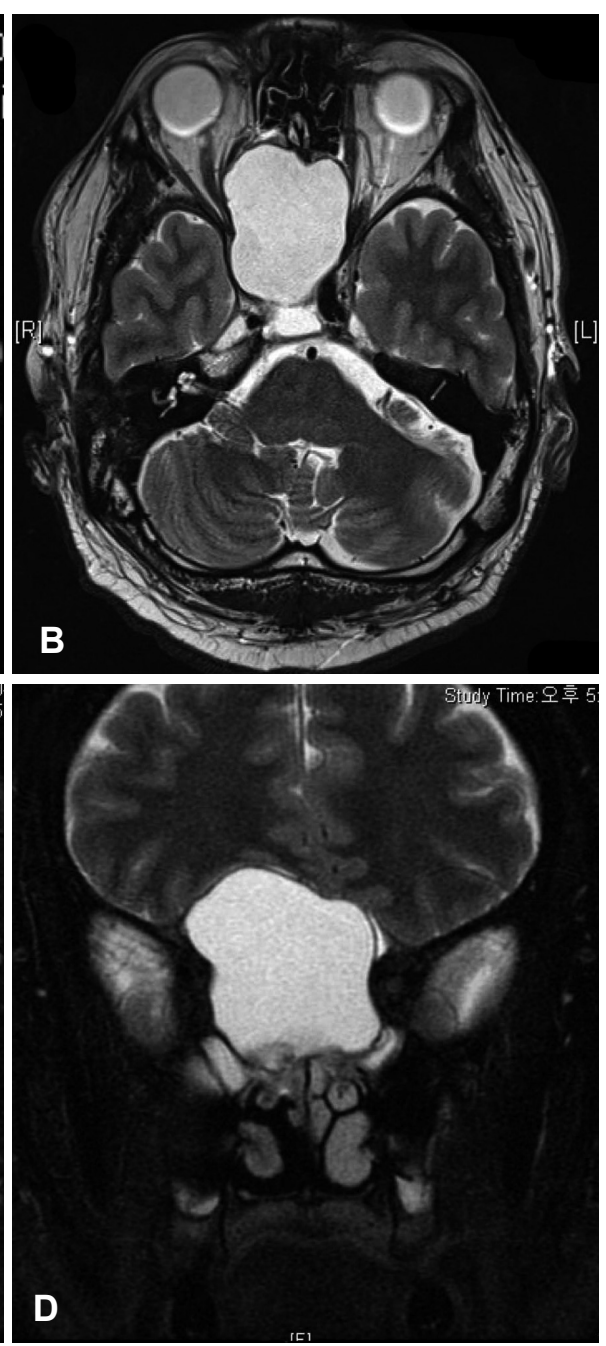

Fig. 4. PNS MRI images from patient 2. A 4-cm, expansile lesion in the sphenoid sinus, with low signal intensity on T1-weighted images (A: axial, C: coronal) and high signal intensity on T2-weighted images (B: axial, D: coronal). PNS: paranasal sinus.

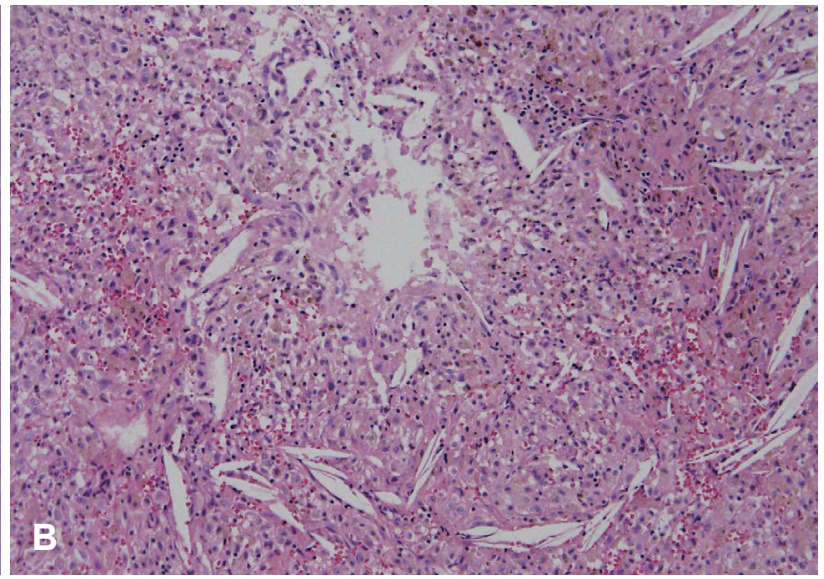




\section{Case 2}

A 49-year-old patient visited our clinic with symptoms of abrupt reduction in visual acuity accompanying three months of mild headache. The patient had a preoperative visual field defect with no lesions on the fundus according to ophthalmologic examination. The patient had no history of nasal trauma or surgery. MRI evaluation showed an expansile cystic mass in the sphenoid sinus. The mass measured about $4 \mathrm{~cm}$ in length and showed hypo-intensity with brain parenchyma on T1WI and high signal intensity on T2WI, suggesting a mucocele (Fig. 4). Endoscopic sphenoid sinusotomy was performed to remove the mass. The posterior wall and the roof of the sphenoid sinus were eroded by the mass, but there was no sign of CSF leakage. The surgical specimen was reviewed by a pathologist and was diagnosed as a cholesterol granuloma. The patient's visual field defect recovered a short time after the surgery. The patient had chronic headaches postoperatively for six months, but CT evaluation revealed a clear sphenoid sinus without recurrence. Four years has passed since the operation, and the patient's headaches have calmed, and no recurrence has been noted.

\section{Discussion}

Clinical manifestations of cholesterol granuloma are usually nonspecific and variable depending on the site of origin. PNS involvement can cause various symptoms such as facial pain, swelling, headache, diplopia, loss of visual acuity, exophthalmos, nasal obstruction, rhinorrhea, or meningitis. ${ }^{7,9-11)}$

The pathogenesis of cholesterol granuloma is still unclear but is thought to be caused by disturbed ventilation, impaired drainage, and hemorrhage. ${ }^{12)}$ Following ventilatory obstruction and lack of drainage of the pneumatized mastoid or sinus bone, air is reabsorbed inside the obstructed cavity, and negative pressure is created, causing hemorrhage or exudation. Previous operations or trauma may result in similar conditions.

Foreign body reactions toward blood, including its products and cholesterol particles from erythrocyte cell membranes, result in cholesterol crystals. Cholesterol crystals are insoluble, causing precipitation and subsequent formation of granulation tissue. ${ }^{12)}$ Mucoceles and cholesterol granulomas share similar pathogeneses. However, Milton, et al. ${ }^{13)}$ has reported that, after obstruction of the natural ostium of the sinus, cholesterol granuloma accompanies hemorrhage, while mucocele can occur without hemorrhage.

Differential diagnosis of cholesterol granuloma includes mucocele, cystic schwannoma, meningioma, paraganglioma, and cephalocele. Cystic schwannoma (T1-iso or hypointense, T2-hyperintense) and cephalocele (T1-hyperintense, T2-hypointense) can usually be excluded by characteristic imaging findings, ${ }^{5,14,15)}$ however, it may be difficult to differentiate cholesterol granuloma from mucocele based solely on CT analysis because both appear as expansile lesions with soft tissue density and thinning or erosion of adjacent bones. On MRI, cholesterol granuloma is known to show high signal intensity on both T1- and T2-weighted images because of the paramagnetic effect of methemoglobin. In contrast, mucocele shows low signal intensity on T1-weighted images, helping to differentiate it from cholesterol granuloma. However, in some cases of mucocele including inspissated proteinaceous materials or internal hemorrhage may occasionally show high signal intensity on T1WI, misleading to the diagnosis of cholesterol granuloma, demanding pathologic confirm for differentiation. ${ }^{5,16)}$

In our cases, the content of the surgical field was filled with viscous fluid with necrotic debris and it was like a mucocele. Shirataki, et al. ${ }^{17)}$ histopathologically classified cholesterol granuloma into three groups depending on the amount of cholesterol clefts, hemorrhagic foci, or various cells. We assumed that if the portion of protein material is less, or long time has passed for degradation of the methemoglobin, cholesterol granuloma can show iso- or hypo intensity in MRI findings as the preoperative imaging.

PNS mucoceles are epithelium-lined and mucus-filled cystic masses resulting from obstruction of sinus ostium and maintaining drainage/ventilation through surgical excision of the capsule may be the ideal treatment theoretically. ${ }^{18)}$ However, total excision of the cyst wall of cholesterol granuloma is not necessary due to the absence of epithelial lining and maintaining long-term patency of the drainage is essential to prevent recurrence. $^{19)}$

\section{REFERENCES}

1) Hwang DJ, Chung YS, Jun SY, Kim YJ, Lee JY, Park IW. A case of compressive optic neuropathy caused by sphenoid sinus cholesterol granuloma. Jpn J Ophthalmol 2009;53(4):441-2.

2) Kang H, Kim JK, Kim Y. Association of cholesterol granuloma and aspergillosis in the sphenoid sinus. Korean J Radiol 2008;9(Suppl): S30-3.

3) Chao TK. Cholesterol granuloma of the maxillary sinus. Eur Arch Otorhinolaryngol 2006;263(6):592-7.

4) Dilek FH, Kiriş M, Uğraş S. Cholesterol granuloma of the maxillary sinus. A case report. Rhinology 1997;35(3):140-1.

5) Weiland DA, Aygun N. An unusual presentation of a cholesterol granuloma in a pneumatized pterygoid process of the sphenoid sinus. Otolaryngol Head Neck Surg 2007;136(1):153-4.

6) Gray WC, Salcman M, Rao KC, Hafiz MA. Cholesterol granuloma 
of the petrous apex and sphenoidal sinus: a case report. Neurosurgery 1985;17(1):67-9.

7) Mallon A, Poletto E, Chennupati SK. Large pediatric sphenoid sinus cholesterol granuloma: case report and review of the literature. Int J Pediatr Otorhinolaryngol Extra 2014;9(3):103-7.

8) Jackler RK, Parker DA. Radiographic differential diagnosis of petrous apex lesions. Am J Otol 1992;13(6):561-74.

9) Bütler S, Grossenbacher R. Cholesterol granuloma of the paranasal sinuses. J Laryngol Otol 1989;103(8):776-9.

10) Kim SS, Moon SK, Kim TY. Cholesterol granuloma in the sphenoid sinus: a case report. J Korean Neurosurg Soc 2001;30(7):921-4.

11) Jun JH, Park JY, Yeo CK, Shon KR. A case of cholesterol granuloma of the sphenoid sinus. Korean J Otolaryngol-Head Neck Surg 2002; 45(3):293-5.

12) Erpek G, Ustün H. Cholesterol granuloma in the maxillary sinus. Eur Arch Otorhinolaryngol 1994;251(4):246-7.

13) Milton CM, Bickerton RC. A review of maxillary sinus cholesterol granuloma. Br J Oral Maxillofac Surg 1986;24(4):293-9.

14) Netra R, Hui MS, Gang MZ, Ming Z. Spinal cystic schwannoma: an MRI evaluation. J Coll Physicians Surg Pak 2014;24(2):145-7.

15) Dobrocky T, Ebner L, Liniger B, Weisstanner C, Stranzinger E. Preand postnatal imaging of Pai syndrome with spontaneous intrauterine closure of a frontal cephalocele. Pediatr Radiol 2015;45(6):936-40.

16) Ahmed M, Joseph E, Mani S, Chacko G, Rajshekhar V. Cholesterol granuloma of the sphenoid sinus: an unusual sphenoid sinus lesion. Neurol India 2012;60(3):332-3.

17) Shirataki K, Okada S, Matsumoto S. [Histopathological study of the "cholesterol granuloma reaction" in the sellar and juxta-sellar tumors]. No To Shinkei 1988;40(2):133-9.

18) Capra GG, Carbone PN, Mullin DP. Paranasal sinus mucocele. Head Neck Pathol 2012;6(3):369-72.

19) Nikolaidis V, Malliari H, Psifidis D, Metaxas S. Cholesterol granuloma presenting as a mass obstructing the external ear canal. BMC Ear Nose Throat Disord 2010;10:4. 